\title{
Understanding the Many Factors that Affect the Success of Organizational Work Teams
}

\author{
Robert J. Trent, Ph.D. a* $^{*}$ \\ a Professor of Management, Lehigh University, Bethlehem, PA 18015, USA. Phone: 610-758-4952 \\ *Corresponding author's email address: rjt2@lehigh.edu
}

\section{A R T I C L E I N F O}

Received: 27-05-2016

Accepted: 04-07-2016

Available online: 08-07-2016

\section{Keywords:}

Critical success factors;

Qualitative analysis;

Teams;

Team leadership;

Team size.

JEL Classification:

\begin{abstract}
A B S T R A C T
After years of experience and research, one might conclude that organizations are confident in their ability to optimize the use of teams. In reality, we do not have to look far to find instances where team performance falls disappointingly short. This article examines the reasons for the success or failure of three organizational work teams. Using information gained from structured interviews involving team members, team leaders, and managers, a set of value-added findings are reached that explain why a particular team was or was not successful.

This paper also presents original quantitative research that examined a variety of factors that affect work team success. It presents insights into a set of important factors that can affect team performance, particularly new findings regarding team size as well as the kind of organizational team model employed.The article concludes with a set of recommendations and policy implications derived from the research.
\end{abstract}

This is an open access article under the terms of the Creative Commons Attribution License 4.0, which allows use, distribution and reproduction in any medium, provided the original work is properly cited.

DOI: http://dx.doi.org/10.18533/job.v1i6.40 ISSN: 2380-4041 (Print), 2380-405X (Online)

\subsection{Introduction}

Several decades ago J. Richard Hackman, a leading expert on group performances aid that teams can yield the kinds of benefits envisioned by their creators. Conversely, he also said that teams can waste the time and energy of members, enforce lower performance norms, create patterns of destructive conflict within and between groups, and make notoriously bad decisions. More recently Hackman commented that there is no question that teams can generate magic. But, he also said not to count on that magic (Coutu, 2009).

One might think that after years of experience and research, organizations would be confident in their ability to use teams. While over the last 40 years an abundance of information on work teams has emerged, this information has not always transferred to subsequent generations of managers, team leaders, and members (Kozlowski and Bell, 2001). An understanding regarding how to use teams is still not an embedded part of many organizational cultures, and new generations of participants are not necessarily exposed to this understanding through academic or workplace training. And, never forget that teams invariably involve humans, something that introduces complexity and inconsistency to any process.

Current research supports the need to better understand how to use organizational work teams. Over half of the respondents participating in a recent research project (described later)agreed that some of their fellow team members lacked the time to support team assignments; the organizational reward system in place did not 
recognize the time and effort required by members to support team objectives; and that communication barriers existed among team members. Just less than half agreed their team faced resistance from others external to the team; managers or executives attempted to control team activities or influence decisions; and that some team members lacked the knowledge, skill, or experience to support their team's assignment(s). These findings hardly suggest an organizational mastery of the teaming process.

This article presents findings from a project that examined the factors that affect the success of organizational work teams. This analysis provides an opportunity to elaborate upon the state of knowledge as it concerns some important team-related topics, which is the primary motivation behind this work. The qualitative findings presented here are also supported by data from a quantitative study of work teams. The article concludes with a set of recommendations and policy implications based on the research findings.

\subsection{The organizational work team study and methodology}

The reasons for the success or failure of teams are varied and not necessarily consistent from team to team, making generalizability an inexact science. Using information gained from in-depth interviews involving team members, team leaders, and managers, a set of conclusions are reached that explain why specific teams were successful or not. Interviews followed a structured approach using an interview guide developed specifically for this research, which appears in the Appendix.

The teams featured here are each part of for-profit companies. Furthermore, each team was cross-functional, meaning that it included members from different functional groups. And, each team conducted its meetings faceto-face rather than virtually. Team size ranged from three to eight members with each team no longer active at the time of the interviews, giving the participants the benefit of hindsight.

A quantitative study, designed specifically to explore further the findings from the case analyses, investigated variety of factors that can affect team success. Electronic invitations were sent to approximately 1,700 individuals selected randomly from a database containing8,000 industry members. Respondents had to have detailed experience with a specific work team to participate, which eliminated a portion of the invited respondents. Also, invalid e-mail addresses resulted in approximately 20 percent of thesurvey invitations returned as undeliverable. The final response rate for the sample was just over 10 percent.

The quantitative research includes data from 140respondentscollected over a three-week period. Respondents provided information based on their experience with a specific work team for which they areor were closely involved. The sample is diverse and includes participants from fifteen functional groups; companies competing in20different industries (primarily based in North America); and annual company sales ranging from less than $\$ 1$ million to over $\$ 5$ billion.

The conclusions reached here "open the door" for elaborating on the many factors that potentially affect team success, something that previous research and the literature does not do well. The opportunity to update and enhance our knowledge of the critical factors that affect team performance is the primary motivation behind this research. To provide a baseline understanding of organizational work teams, Table 01 summarizes relevant findings of some of the most respected academic researchers within the organizational work team domain.
Hackman, 1990
Table 01: Summary of literature review conclusions by leading academics
Hackman, 1985
A team satisfies certain characteristics: it must be a real, self-managed or self- regulated group with an intact social system; it must have one or more tasks to perform for which the members are held mutually accountable; and it must operate within a formal organizational context
Team effectiveness is defined in terms of three criteria: the productive output of the team should meet or exceed the standards of those who receive or review the output; the team's experience should enhance the capability of members to work together on future assignments; and the team experience should satisfy rather than frustrate the personal needs of members
A team's task importance affects a member's motivation to pursue that task
Guzzo, 1986
Takeuchi and Nonaka, Subtle control exerted my managers is a powerful yet simple concept to influence 1986 teams in ways that enhance their chances for success
Hillman, Schwandt, and Feedback is the process of providing information to staff, employees, or team Bartz, 1990
London, 2008 members about their performance pertaining to job expectations The critical linkage between effective feedback and improved performance is well known in the academic literature 
Peters and O'Connors, A set of important but often-overlooked variables includes the resources that can 1980 promote or interfere with the translation of team member abilities and motivation into effective performance

Guzzo, 1986

Levine and 1990

Kozlowski and Bell, 2001

Likert, 1961

Zenger, Musselwhite Hurson, and Perrin, 1994 Kozlowski and Bell, 2001

Wicker, Kirmeyer, 1976

Stodgill, 1981

McGrath, 1984

Latane, Williams, and Karkin, 1979

Hoffman, 1979
Organizational resources are a primary determinant of team effectiveness

Moreland, Roles are shared expectations about how a particular team member ought to behave. Member roles potentially influence team effectiveness when a person lacks the knowledge, ability, or motivation to play a role effectively or team members disagree about how to carry out a role or who should play it

Most team effectiveness models recognize the critical role played by team leaders. However, relatively few studies have attempted to articulate the specific role of team leaders

Team leaders exert a disproportionate effect on group effort, cohesion, goal selection, performance norms, and goal attainment

Organizations usually underestimate the time and skills required to take on a formal team leadership position, thereby exposing teams to greater risk

While an abundance of information on work teams has emerged, this information has not always transferred to subsequent generations of managers, team leaders, and members

Members of larger teams often report less satisfaction from participation, less opportunity to influence decisions, and complain of poor coordination of activities and assignments

As team size increases, members have less opportunity to participate or lead with fewer members initiating leadership acts

Process loss results from difficulties associated with coordinating team member activities, motivational problems, and inefficiencies that result when members work together on teams. Process loss increases at an increasing rate as a team adds members

d As group size increases, so does the probability of social loafing. Social loafing describes the tendency of individuals to put forth less effort as group size progressively increases

Teams with different personality types, leadership abilities, types of training, and points of view are usually more creative and innovative than teams with similar member characteristics

\subsection{Results and discussion}

The following presents a set of factors that affected the success of three work teams based on detailed interviews with team members, leaders, and managers. Each team satisfies Hackman's criteria defining a formal team-the team was a real, self-managed or self-regulated group with an intact social system; the team had one or more tasks to perform for which the members were held mutually accountable; and the team operated within a formal organizational context (Hackman, 1990).As mentioned, each team was no longer active at the time of the interviews, allowing the participants the benefit of hindsight.

\subsection{Scenario \#1 - Developing a company-wide information technology system}

The team featured in this scenario is part of a company that manufacturers transportation equipment. The company maintains a large network of distribution centers to support its dealer aftermarket (i.e., repair) business. A vice-president decided the time had come to standardize and update the technology platform used by all of the company's distribution facilities. Hechartereda cross-functional team and charged it with developing a proposal for a common information technology system, including hardware and software, for use at each distribution facility. This executive selected five employees to be part of the project team and solicited the support of a leading high-tech company, which willingly provided three individuals to participate. He assigned the team its own workspace and removed team members from their normal job responsibilities. He also informed managers outside the team that team members were not to be disturbed with non-team-related matters.

This executive made several points quite clear during the team's kick-off meeting. First, he explained that the primary objective of the team was to develop the concept for a new system. As such, later groups would engage in detailed design that might alter, perhaps significantly, the team's recommendations. Second, this 
executive said he wanted project updates at the end of two weeks and four weeks, with a final presentation at the end of the sixth week. Third, he explained that he had created a financial account to support team expenses, including any travel and living costs incurred during the course of the team's work. The team had authority to authorize funds from that account. Finally, this executive explained clearly why each member had been selected for the team.

Not surprisingly, this team delivered a well-crafted proposal at the end of six weeks. While it became the responsibility of others to design and implement the new system, the final system looked remarkably similar to the concept proposed by the team. This new system provided a set of benefits and functionality that was industry leading. Why was this team so successful?

Challenging and Meaningful Task Assignment. This team's executive sponsor understood the importance of assigning an important and meaningful task to the team, an importance that is well understood in the literature. Research findings indicate that a task's importance affects a member's motivation to pursue that task (Guzzo 1986). It is easy to appreciate that goal oriented people respond positively when presented with challenging assignments.

Team members understood that they were working on a visible and important project. They recognized that any new system would affect every facility, employee, and functional group within the aftermarket division. The new system would also have a significant impact on customer service levels. It was a strategic task whose outcome would affect this company's competitive position.

While the temptation may exist to assign a team to just about any task, the use of teams should be selective. From the quantitative portion of this research, over $90 \%$ of respondents are in some level of agreement that the team for which they were responding was assigned a task that warranted the use of a team. From this set of respondents it appears that the use of teams is a relatively well-thought out organizational decision.

Subtle rather than Blatant Management Control. Selecting team members, assigning a specific task, and requiring the team to report its progress at regular intervals are examples of the executive leader practicing "subtle control." Subtle control is a powerful yet simple concept that leaders should routinely practice to influence teams in ways that enhance their chances for success (Takeuchi and Nonaka, 1986). It provides a way to exert that influence while avoiding the temptation to micromanage.

Executive leaders can practice subtle control in a variety of ways. They can identify the projects or tasks that a team pursues, select team members, select the team leader, require performance updates at regular intervals or milestones, establish the broad performance targets that teams use when establishing goals, and hold teams accountable for their success of failure. Subtle control recognizes that while empowerment can be attractive, relinquishing complete control over the teaming process may not be so attractive.

Effective Feedback. Feedback is the process of providing information to staff, employees, or team members about their performance pertaining to job expectations (Hillman, Schwandt, and Bartz, 1990). Members indicate the vice president (i.e., the team sponsor) effectively used the two and four week review sessions to question team members about their progress as well as to provide constructive feedback. This feedback provided the team with valuable guidance as it progressed toward its final outcome.

Why is there such a strong link between effective feedback and performance? We know that goal directed effort is greater in teams that receive feedback regarding their progress. Furthermore, a team's performance increases as the feedback becomes more complete. Effective feedback also affords an opportunity to correct a problem that, if left unattended, will likely become more severe. And, effective feedback usually involves some agreement or plan for moving forward. If delivered properly, feedback also offers an opportunity to strengthen relationships and performance. The important linkage between effective feedback and improved performance is well known in the academic literature (London, 2008).

The quantitative portion of this research provides some interesting findings related to feedback. Strong correlations exist (greater than .50) between respondents who say they receive effective feedback and their belief that(1) their team has a qualified leader, (2) team members are clear about their role on the team, and (3) the goals of the team are clear. As will be discussed, providing feedback is a primary responsibility of team leaders.

Resources Available to Support Team Activities. We have known for some time that a set of important but oftenoverlooked variables includes the resources that can promote or interfere with the translation of team member abilities and motivation into effective performance (Peters and O'Connors, 1980). In a critique of group decision 
making and effectiveness, Guzzo (1986)argued that organizational resources are a primary determinant of team effectiveness. Far too many teams and their executive leaders mistakenly take the availability of resources for granted. Table 02 identifies a set of organizational resource categories that teams usually require at some point.

Table 02: Team-related resource categories

Job-Related Information

The data and information required to support team analysis and performance

Materials and Supplies

The routine materials and supplies required to support team activities

Required Help from Others

The services and assistance from others external to the team, such as as-needed members

Time Availability

The amount of time that members can commit to team activities

Executive Management Commitment

The overall support that executive management demonstrates toward work teams and teaming

Adapted from Peters and O'Connor
Tools and Equipment

The specific tools, equipment, technology, and information technology required to support team efforts

\section{Budgetary Support}

The financial resources, not including salaries, required to support a team's task

Team Member Task Preparation

The personal preparation and experience of team members to be part of a team as well as their readiness to perform immediate tasks

Work Environment

The physical characteristics of the team's work environment

Customer and Supplier Participation

The support that customers and suppliers provide when involvement is beneficial

The teamfeatured in this scenario visited other facilities and companies to identify best practices. These trips benefited from the availability of budget to support travel and living expenses. The team was also able to commit a full-time effort to the project, making the availability of time an invaluable resource. Still another resource, executive commitment, was evident at the onset.

In this case it is hard to overestimate the value provided by the high tech company, which represents support provided from others external to the team. These external members provided expertise about available software and hardware, system features, technology trends, and technical feasibility. The systems capabilities the team had access to internally did not compare with a company that was at the forefront of information technology development.

From the quantitative portion of this research, a strong correlation(.55) exists between respondents saying that management commitment of resources is at a level necessary to support their team's assignment and the ability of their team to achieve or exceed its performance expectations. The availability of specific resources has the potential to separate marginally performing from exceptionally performing teams. While every team is somewhat unique in the resources it requires to be successful, teams that are resource rich, all else equal, should be more successful than resource deprived teams.

Member Role Understanding. The team sponsor understood clearly the importance of selecting qualified individuals and then making sure that each member understood his or her formal role on the team. Role refers to the set of expectations that team members share concerning the behavior of a person who occupies a given team position and how certain positions relate to the team's task. Another perspective defines roles as shared expectations about how a particular team member ought to behave (Levine and Moreland, 1990).

The potential for dysfunctional team performance exists if confusion concerning the role of individual members is present. Member roles potentially influence team effectiveness when a person lacks the knowledge, ability, or motivation to play a role effectively or team members disagree about how to carry out a role or who should play it (Levine and Moreland, 1990). Research further indicates that role conflict contributes to increased tension and decreased individual and team productivity. Failing to address this importance topic exposes a team to serious risk.

Quantitative data reveal that role understanding correlates strongly with some important team-related factors. First, and perhaps most importantly, role understanding correlates with team performance at a level higher than 
any factor evaluated during the quantitative research (a correlation of .61 exists between team members who say they understand clearly their role and their team's performance rating). Second, members who say they understand their role on the team are more likely to say:

- Through team interaction their team arrives at better decisions than if team members worked alone (correlation of .56)

- Trust is present between members (.54)

- Members work as a collective unit rather than individual members working separately on tasks $(.57)$

- The team receives effective feedback (.51)

- The team's goals are clear (.66)

- The input or contribution of departments and team members is considered equally (.65)

- The team leader is qualified to lead the team (.64)

The relationship between role understanding and other important factors is one of the strongest identified during the quantitative portion of this research.

Proper Team Design. Figure 1 presents a model that segments work teams according to their duration and member time commitment. The executive in this scenario clearly understood the structure that was best suited to support this team's task. Matching the right model to the team's task is an important consideration during team planning.

Figure 1: Organizational work team models

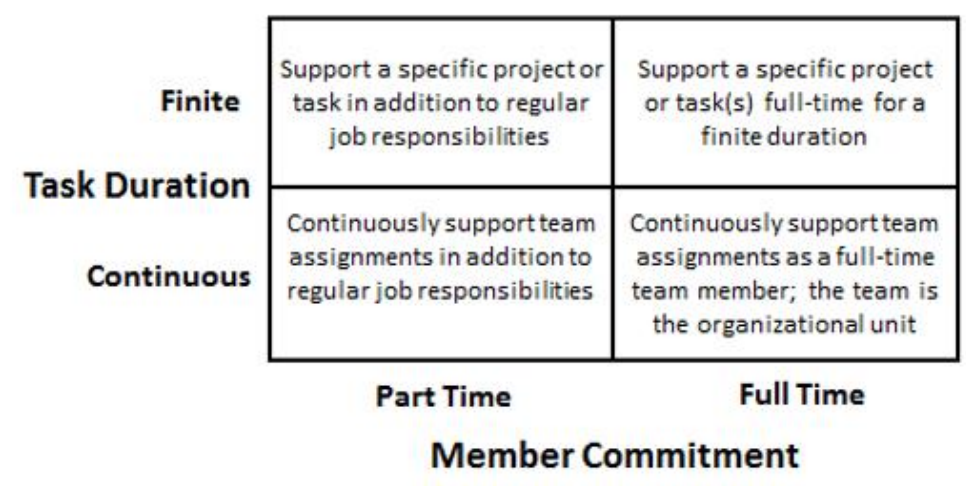

While some organizations create teams staffed with full-time members, as was the case here, teams staffed with part-time members remains a popular yet challenging design option.

Organizations that rely on part-time teams typically maintain their existing functional structure with team-related duties added as additional responsibilities. A part-time structure creates a de facto matrix organization where team members report to multiple entities-the team and their functional group. This has the potential to create stress and conflicting time demands.

Expected duration is also an important consideration. A major challenge when using continuous rather than finite teams (i.e., teams with a defined end point, such as project teams) involves maintaining member intensity and performance. The early positive effects of team formation often taper off and even diminish when members work over an extended period. Selecting the proper team model is no accident. It is the result of a well-thought out decision that matches the right model with the team's task.

A major objective during the quantitative research was to understand if differences exist across the four quadrants featured in Figure 1. Table 03 presents differences across the quadrants that are most pronounced of 23 items evaluated by respondents. The first figure in the table represents the percent of respondents that are in some level of agreement with a particular statement.

The figure below each percentage is the average value for all respondents in that category where $1=$ strongly disagree, 2 = disagree, $3=$ slightly disagree, $4=$ slightly agree, $5=$ agree, and $6=$ strongly agree with a statement. Lower values are more desirable than higher values given the wording of the statements. 
Table 03: Team Operating Model Comparisons

Item

Continuous

Team members are confused about their role on this team

This team is a collection of individual members working on separate tasks - we have yet to become a collective unit

This team has a member(s) who does not support this team's goals

Some team members fail to commit the effort required to support the team's task requirements

This team has a member or functional group that dominates the team's agenda

Our performance evaluation and reward system does not recognize the time and effort required by members to support this team's objectives At least some of this team's members lack the time to support team assignments

Average across 23 items

Average team performance rating

Average team size
PT /

$32 \% *$

$2.79 *$

PT /

Finite

$32 \%$

2.68

$25 \%$

2.64

3.32

$42 \%$

2.84

$47 \%$

3.42

$47 \%$

3.47

$63 \%$

3.58

$68 \%$

3.95

$38 \%$

2.96

4.39

6.0

$\mathrm{N}=23$
$36 \%$

2.79

$46 \%$

3.29

$46 \%$

3.29

$57 \%$

3.86

$49 \%$

3.70

$32 \%$

2.79

4.62

6.3

$\mathrm{N}=30$
FT /

Continuous

$20 \%$

2.31

$24 \%$

2.59

$22 \%$

2.39

$27 \%$

2.63

$27 \%$

2.63

$43 \%$

3.32

$40 \%$

2.98

$31 \%$

2.70

5.19

5.19
6.6

$\mathrm{N}=58$

FT /

Finite

$17 \%$

2.08

$33 \%$

2.50

$8 \%$

2.42

$17 \%$

2.42

$17 \%$

2.42

$42 \%$

2.75

$42 \%$

3.25

$26 \%$

2.47

5.21

6.3

$\mathrm{PT}=$ Part Time, FT $=$ Full Time commitment on the part of the team member

*Percent of respondents that slightly agree, agree, or strongly agree with the statement

*Figure below the percentage represents an average value for that group along a six-point scale where $1=$ strongly disagree, $2=$ disagree, $3=$ slightly disagree, $4=$ slightly agree, $5=$ agree, and $6=$ strongly agree

This table reveals that the model employed in this scenario (full-time/finite model) placed the team in a better position to succeed. Respondents indicate that teams operating in a part-time/continuous environment are more likely to achieve lower performance compared with the other three quadrants. They are also more likely to have team members who (1) are confused about their role on the team; (2) are part of a team that fails to become a collective unit; (3) are more likely not to support the team; (4) lack the time to support team assignments; (5) put forth lower team effort; and (6) experience a member or functional group attempting to control team assignments. Each is an undesirable outcome linked to the lower left-hand quadrant of Figure 1.

Well-Understood Authority Levels. Thinking about what a team can and cannot do in terms of authority is often overlooked when forming work teams. Here, the executive leader was proactive regarding this important topic. First, he allocated special funds so the team could pursue its task without constantly seeking time-consuming permission. Second, he made it clear that the team did not have final decision-making authority. Team members understood they were making recommendations rather than binding decisions, helping to avoid confusion at a later date. The next case elaborates more fully on team authority.

Even before this team began its work, a set of decisions were made that helped ensure team success. Unfortunately other teams are not always so fortunate, which the next case illustrates.

\subsection{Scenario \#2: Working to improve supply chain effectiveness}

Executive leaders at a household furnishings company became frustrated when the team they had assembled to improve supply chain performance failed to achieve much over the course of a year. It soon became clear that this team faced serious hurdles that practically guaranteed its failure. Whenever team members entered a work area to discuss or initiate improvement ideas, supervisors challenged the team's authority to make changes. And, the executive leader that sponsored this team did not show much interest in the team after its launch. Some team members also complained privately about the effectiveness of their team leader.

Members further admitted they did not fully understand supply chain management. While they were comfortable with issues pertaining to their own functional groups, they were not so comfortable operating within a broader organizational context, which is where supply chain management operates. As results were not forthcoming, members became frustrated and began to migrate back to their functional jobs at the expense of their commitment to the team. The lack of success experienced by this team also affected this company's ability to subsequently use teams. Why was this team so unsuccessful? 
Ineffective Leadership. Most team effectiveness models recognize the critical role played by team leaders (Kozlowski and Bell, 2001). Over 50 years ago Likert concluded that team leaders exert a disproportionate effect on group effort, cohesion, goal selection, performance norms, and goal attainment (Likert, 1961).While many variables affect team success, the influence of the leader is especially important. Unfortunately, the team featured in this scenario suffered from ineffective leadership at the executive and team level.

The formal role assumed by a team leader places this individual in a unique position to promote group interaction, guide teams toward consensus, establish high performance norms, promote member effort, and see to it that team tasks are important, challenging, recognized, and rewarding. Only a formal leader can perform many of the responsibilities associated with team leadership. Organizations usually underestimate the time and skills required to take on a formal team leadership position, thereby exposing teams to greater risk (Zenger, Musselwhite, Hurson, and Perrin, 1994).

Interestingly, relatively few studies have attempted to articulate the specific role of team leaders (Kozlowski and Bell, 2001).While different sources will have their own perspective regarding what defines an effective leader, most would likely agree that a team leader must satisfy a variety of responsibilities to be effective. Examples of team leader responsibilities include securing member involvement; managing team conflict; maintaining team focus and direction; securing resources; preventing team domination by a member(s) or function(s); dealing with obstacles confronting the team; coordinating multiple tasks and managing the status of team assignments; helping the team establish goals; clarifying and/or defining each member's role; providing performance feedback to the team and/or individual members, and guiding the team towards consensus decisions (Trent 2004).

Quantitative data further support the importance of a qualified team leader. Respondents who indicate their team leader is effective are also likely to say (1) team members are clear regarding their role on the team (correlation of .64);(2) team interaction leads to better decisions (.53);(3) the team is a collective unit rather than a collection of individuals (.52);(4) the team receives feedback regarding how well it is performing (.54);(5) the team has clear goals (.51); and(6) the input or contribution of team members is considered equally (.56). The presence of a qualified team leader also correlates highly (.55) with team performance. Ignoring the linkage between leader effectiveness and team performance is one of the most serious mistakes that an organization can make.

Lack of Authority. Just as the first scenario featured a team that was clear regarding what it could and could not do, executive leaders herefailed to address this issue. The resulting challenges that the team received to its authority, particularly from functional managers, was predictable. The inevitable outcome was conflict and confusion, not only within the team but also with others external to the team.In hindsight, executive managers should have conveyedearly onthe boundaries within which the team had authority to operate and make decisions. A team charter that formalized the team's authority would have been beneficial. Of course, only those individuals and teams that understand how to exercise authority and have the ability to do so should be granted authority.

Various team-based models include a team's decision authority as a direct predictor of success. Teams differing in their level and kinds of decision authority often demonstrate different performance. Teams with internal authority, for example, of ten exhibit greater process efficiency, greater team effort, and greater satisfaction with teaming as a process. Qualified teams with greater external decision-making authority (i.e., ability to make decisions that bind an organization) should, on average, be able to channel that authority into decisions that support better organizational performance.

If the reason for using a team is to improve decision quality and goal achievement, then qualified teams should be granted the right kinds of authority. Team performance often suffers when executive managers ignore, disregard, or alter team decisions, particularly when a team believes it has the authority to act. The fact that managers in this scenario freely challenged the team indicates that team authority was an unresolved issue.

Challenging Team Model. This team pursued a part-time/continuous assignment with no specific thought given to the team's duration or life cycle .As mentioned, a part-time model creates a de facto matrix structure where team members report to the team and to a functional group, something that often leads to stress. The usual warnings on the diminished performance over time of continuous teams apply here.

Lack of Executive Support. Just as the first scenario featured extensive executive support, this scenario featured the opposite. A clue that suggested a lack of executive engagement was the lack of communication between the team and its executive sponsor. This not only prohibited the team from receiving valuable feedback, it also conveyed a lack of interest by executive management. Several team members perceived that the team was established so executive management could say they were using teams. When this is the case the use of teams 
becomes an activity rather than a way to realize accomplishments that are above and beyond what is available through traditional organizational methods.

Broad Assignment with Few Formal Goals. This team's reason for existence was likely too broad and open-ended. After being told to "improve supply chain performance "it is unrealistic to expect clear, unambiguous goals to emerge. Was this team supposed to improve supplier delivery, manage inventory more effectively, improve product quality, reduce costs, or develop better supply chain systems? This resulted in inadequate team goals being the inevitable result. And, an absence of goals meant an absence of accountability for achieving specific results. Upon closer examination it became evident that the kinds of goals sought from a team responsible for improving supply chain performance were not the kinds of goals these team members understood. This team engaged in minimal goal setting with a predictable lack of success.

IIl-prepared Team Members. The first scenario addressed the importance of selecting members with the knowledge, skills, and abilities required to support a specific assignment. The emphasis in this scenario was on selecting members from different functional groups, which on the surface appears to be a worthy objective. Just because a team has members from different functional specialties, however, does not mean these members can operate cross-functionally. In fact, this was the first cross-functional team experience for most of these members. From the quantitative portion of this research over 40 percent of respondents said that some members of the team for which they were responding lacked the knowledge, skill, or experience to be part of the team.

In retrospect this team did not have much working in its favor. Poor planning combined with ineffective leadership and a demonstrated lack of accomplishment helped ensure this team would fail to meet even a reasonable level of performance expectations. Perhaps more importantly, a lack of success affected this company's willingness to expand its subsequent use of work teams.

\subsection{Scenario \#3 - Developing a new scheduling system}

Executive managers at a packaging facility decided that a need existed to develop a state-of-the-art scheduling system. The existing system, which was not much of a system at all, scheduled parts for packaging from suppliers in the sequence for which they were received. First come-first serve was the order of the day.

Management was acutely aware that a first come-first serve system, while simple and straightforward, had serious flaws. Assuming that an item's priority for packaging is a function of when an item arrives at the facility is questionable at best. Some suppliers are late with their deliveries, making a move to the front of the que necessary but not easily accomplished. Furthermore, a first come-first serve system provides no insight into customer demand. Some items may have backorders pending and warrant immediate packaging. Other items have ample stock available and should not be packaged immediately.

A team comprised of two internal IT professionals and one from the packaging facility worked 18 months to develop anew scheduling system. While this project resulted in some changes that improved the flow and efficiency of the facility, the primary objective of providing demand-driven, daily work schedules for each piece of packaging equipment was far from successful. For reasons that will be explained, work center supervisors often failed to adhere to the daily schedule generated by the new system. Some of the scheduling algorithms were also found to contain inaccuracies, something that affected the generation of a valid schedule. Other serious issues confronted the team, few of which were identified or considered prior to project development. Why did this team and the new scheduling system fail to achieve its primary objectives?

Inadequate Team Size. Perhaps the most serious problem that confronted this team concerned its size. The packaging facility required major physical modifications to support the new system, IT support beyond what the team members could provide, and specialized support to develop the scheduling algorithms. The presence of some major tasks overwhelmed the capacities of three individuals. It also made external help from others, a resource that was not always forthcoming, especially critical. The challenges surrounding a small team size could have been mitigated by adding additional core members or formally designating as-needed members, something that did not occur here.

This is a good time to elaborate upon team size issues. Both smaller and larger teams often face issues that affect team success. Members of larger teams, for example, often report less satisfaction from participation, less opportunity to influence decisions, and complain of poor coordination of activities and assignments (Wicker, Kirmeyer, Hanson, and Alexander, 1976). And, as size increases, individual members also have less opportunity 
to participate or lead with fewer members initiating leadership acts (Stodgill, 1981). We also know the pressure to conform to a team's majority position increases as team size increases, a condition that can contribute to something called groupthink.

Large teams are often affected by two phenomena-social loafing and group process loss. Social loafing, first studied in 1913 and at multiple times thereafter, describes the tendency of individuals to put forth less effort as group size progressively increases (Latane, Williams, and Karkin, 1979; Cherry, 2015). A second condition associated with larger groups is process loss. Process loss results from difficulties associated with coordinating member activities, motivational problems, and inefficiencies that result when members work together on teams (McGrath, 1984). And, process loss increases at an increasing rate as a team adds members. Size becomes an issue when the number of team members increases beyond a point that allows effective communication and coordination.

Table 04highlightsvariousissuesassociated with larger teams from the quantitative portion of this research. ${ }^{1}$ As team size increases the probability also increases that members will say they are confused about their role on the team; the team is a collection of individual members working on separate tasks rather than a collective unit; the team has a member(s) who does not support this team's goals; some team members fail to commit the effort required to support the team's task requirements; and the performance evaluation and reward system does not recognize the time and effort required by members to support this team's objectives. The potential consequences associated with larger teams should cause team planners to think carefully before using them. And, if larger teams are used, careful thought must be given to how manage the risks that naturally come with their use.

Table 04: Team size comparisons

\begin{tabular}{|c|c|c|c|}
\hline Item & Smaller & Medium & Larger \\
\hline \multirow{2}{*}{ Team members are confused about their role on this team } & $18 \% *$ & $23 \%$ & $32 \%$ \\
\hline & $2.36^{*}$ & 2.30 & 2.71 \\
\hline \multirow{2}{*}{ Communication barriers exist among team members } & $46 \%$ & $55 \%$ & $66 \%$ \\
\hline & 3.18 & 3.45 & 3.78 \\
\hline \multirow{2}{*}{ Distrust exists between team members } & $5 \%$ & $25 \%$ & $36 \%$ \\
\hline & 1.82 & 2.66 & 3.02 \\
\hline \multirow{2}{*}{ This team has a member(s) who does not support this team's goals } & $9 \%$ & $30 \%$ & $34 \%$ \\
\hline & 1.82 & 2.57 & 2.93 \\
\hline \multirow{2}{*}{$\begin{array}{l}\text { Some team members fail to commit the effort required to support the } \\
\text { team's task requirements }\end{array}$} & $18 \%$ & $25 \%$ & $53 \%$ \\
\hline & 2.95 & 2.62 & 3.60 \\
\hline \multirow{2}{*}{$\begin{array}{l}\text { Team members lack the tools to support effective communication and } \\
\text { interaction }\end{array}$} & $5 \%$ & $19 \%$ & $28 \%$ \\
\hline & 2.05 & 2.38 & 2.80 \\
\hline \multirow{2}{*}{$\begin{array}{l}\text { Our performance evaluation and reward system does not recognize the } \\
\text { time and effort required by members to support this team's objectives }\end{array}$} & $41 \%$ & $43 \%$ & $64 \%$ \\
\hline & 3.09 & 3.19 & 4.00 \\
\hline \multirow{2}{*}{ Destructive conflict occurs between team members } & $14 \%$ & $17 \%$ & $28 \%$ \\
\hline & 2.05 & 2.34 & 2.54 \\
\hline \multirow{3}{*}{$\begin{array}{l}\text { At least some of this team's members lack the time to support team } \\
\text { assignments }\end{array}$} & $33 \%$ & $60 \%$ & $45 \%$ \\
\hline & 2.71 & 3.49 & 3.50 \\
\hline & $25 \%$ & $30 \%$ & $37 \%$ \\
\hline \multirow{3}{*}{$\begin{array}{l}\text { Average across all } 23 \text { items } \\
\text { Average team performance rating }\end{array}$} & 2.54 & 2.66 & 2.98 \\
\hline & 4.92 & 5.09 & 4.65 \\
\hline & $\mathrm{N}=24$ & $\mathrm{~N}=47$ & $N=60$ \\
\hline
\end{tabular}

*Percent of respondents that slightly agree, agree, or strongly agree with the statement

*Figure below the percentage represents an average value for that group along a six-point scale where $1=$ strongly disagree, $2=$ disagree, $3=$ slightly disagree, $4=$ slightly agree, $5=$ agree, and $6=$ strongly agree

Inadequate User Training. Like many projects, this team's timetable proved to be too aggressive, especially for a smaller team. As the timetable lengthened, the development team came under pressure from management to launch the system. As a result, the team overlooked some important tasks, including committing time and resources to user training.

Inadequate training ensured that supervisors, material handlers, machine operators, and staff were not familiar with the new system. To internal users the scheduling logic was a black box that magically presented a sequenced list of work. A lack of training system had an obvious effect on the system's launch and, perhaps more importantly, its acceptance and use. As with many systems, development was "pushed" from above onto those who had to make

\footnotetext{
${ }^{1}$ In this research teams with four or fewer member were classified as smaller teams; 5-7 members were classified as medium teams; and teams with eight or more members were considered larger teams.
} 
the system work. In retrospect, the need to work with those who would use the system day-to-day became evident at too late a date. Never assume that what appears obvious to system developers is obvious to those who will use a system.

Misaligned Measures and Goals. Since individuals typically behave according to how they are rewarded, poorly designed measurement systems can conflict with the objectives of any change. In this case a misaligned measure countered what the development team was trying to achieve through daily work schedules.

The work centers within this facility were measured historically on the number of pieces packaged per hour, even if that resulted in packaging items that were not currently required by downstream entities. Facility supervisors understood how they were measured and they behaved accordingly. Longer production runs meant greater efficiencies.

The new system stressed an entirely new set of objectives. Instead of emphasizing long production runs, the system often replaced longer runs with shorter runs, as defined by a sophisticated algorithm, to avoid packaging unneeded quantities. This meant that each work center would likely see more part numbers scheduled each day but at lower quantities. Additional part numbers would mean more machine changeovers, which means more equipment downtime, which means a likely decline in pieces packaged per hour. Unfortunately, supervisors continued to be measured by machine efficiency, resulting in behavior that often contradicted the daily schedule. The lesson here is to perform a detailed assessment of performance measurement systems prior to making any changes to ensure alignment.

Failure to Manage the Change Process. Because this team was responsible for not only system development but also system implementation (unlike the first scenario), the need to manage the change process became critical. As mentioned, part of the fault in implementing this system involved a lack of training and misaligned performance measures. Another issue concerned the approach taken by the team to launch the new system. Instead of launching in phases, which would require more time, the team responded to external pressure and decided on an "all at once" or "big bang" system launch (a term used by the team).

For a variety of reasons the "big bang" approach did not work well. This facility consists of four very different work centers containing dozens of different types of packaging equipment, each with its own set of nuances that were not always obvious during system development. A phased approach would have allowed the team to address these subtleties in a more manageable way by allowing the team to identify and localize any issues that affected particular work area.

External Resistance to the New System. This company relies on a material planning group that determines when and what to order from suppliers. The only determinant about whether a part is scheduled for packaging under the new system is an unbiased calculation of that part's system-wide priority. Material planners, however, were measured on how fast their individual parts flowed through the supply chain. The parts that mattered most to these planners were their own parts.

It was not long before complaints arrived about parts not being scheduled that were at the top of an individual planner's list. To appease these planners the development team modified the system to allow planners to submit selective overrides to a part's priority. Unfortunately, planners spent a progressively larger part of their day submitting overrides to the scheduling system to ensure their parts would appear on the schedule. This created inefficiencies and wreaked havoc with the daily schedule. It also affected, and not in a good way, the primary objective of the scheduling system, which was to create an unbiased prioritization of work. An important lesson here is to minimize manual overrides to a system. Otherwise, what is the point in having a system?

Inadequate Human Resource Support. This scenario highlights the importance of external support as a critical resource. Here, the scheduling logic was intended to load an amount of work onto a piece of equipment that represented a day's work. To do this the system developers relied on an industrial engineer to develop the scheduling algorithms for each machine center.

The industrial engineer simply input historical averages into the scheduling algorithms for each machine center, even for machines that packaged parts with widely variable packaging times. As the team became preoccupied with other matters, it failed to grasp the damage that averages caused when parts were scheduled that did not get packaged at the "average" rate. The industrial engineer was not formally designated as an "as needed" resource and saw no reason to commit a major work effort. After the magnitude of the problem became clear, team members became angry, at one point publicly accusing the engineer of taking shortcuts. Needless to say, this affected any semblance of a working relationship that existed between the team and the engineer. Other instances of inadequate external support also plagued this team. 
This analysis reveals a set of hurdles faced by this team, most of which were self-inflicted. In retrospect, this project, like most projects that fail to live up to expectations, would have been more successful if those involved understood the many issues involved when planning to use work teams and how to manage the change process, including involving important stakeholders early.

\subsection{Managerial guidance}

Something that should be evident from this discussion is that the use of teams is a complex undertaking. Literally dozens of factors have the potential to affect team success. And, a precise understanding of what affects success or failure often varies from team to team. The challenge becomes one of taking the insights gained from these cases to develop inductively a set of managerial recommendations that enhance the probability of a successful team outcome. ${ }^{2}$

The teaming process starts with leadership. Many positive outcomes flow from the presence of effective leadership at the team and executive level. During the quantitative portion of this research over $90 \%$ of participants said the team for which they were responding had a formally designated team leader. Selecting a team leader requires careful consideration early on during the team planning process. Never assume that an individual automatically has the qualifications, experience, or training to assume demanding team leadership responsibilities. Even if a team has no formally selected team leader, the probability that a leader will emerge increases as team size increases. The question becomes whether the emergent leader has the ability to lead the team effectively.

Understand the factors that relate to team success. The time to think about what is going to impact team success is during the planning phase of team formation. During the quantitative portion of this research a set of items correlated highly with team effectiveness. In other words, as a team's performance increased (or decreased), certain factors were also likely to increase (or decrease) in terms of their correlation with team performance. Most of these items relate directly to those identified during the qualitative portion of this research. In particular, the items that correlate the highest with team performance include:

- Effective team leadership

- Clarifying member role understanding

- Working as a collective unit rather as a collection of individuals

- Creating an environment that is conducive to team interaction

- Clearly established and articulated goals to guide team actions

- Access to tools that support communication and team interaction (especially important as virtual teams become increasingly popular)

- Commitment of required resources to support team tasks

Managers are advised to consider the importance of these factors when planning to use an organizational work team.

Do not discount the importance of team size. Only after determining that a team is an appropriate organizational response should managers identify the skills, knowledge, and abilities required to support a task. This, in turn, affects team size. The findings presented here regarding size should not escape the notice of managers. Team size becomes an issue when the number of members increases beyond a point that allows the effective coordination of activities, although teams that are too small present their own challenges. As reported in Table 04, members of larger teams report a variety of less than desirable outcomes from team interaction. While there is no accepted standard of what defines a large team, most observers would agree that teams exceeding eight members begin to invite coordination and commitment issues.

The right structure or model can affect team success. An earlier section addressed this important topic in detail. A key finding is that teams staffed by part-time members, particularly those that operate in a continuous rather than finite environment, usually present challenges. Not only do members experience conflicting demands on their time, continuous teams usually progress through a life cycle that, much like products, features a "decline" phase. Identifying the best model given a specific task is an essential part of the planning process.

Think about team authority earlier rather than later. A potential area of conflict, and one that requires early attention, relates to the authority granted to a team. Whether explicitly stated or not, teams have varying degrees of authority to perform their tasks or make decisions. Teams may not understand the limits to their authority because managers have ignored this issue, something that often results in misunderstandings and conflict. A

${ }^{2}$ Inductive thinking is defined here as the development of general laws, principles, or findings based on the observation of particular instances. 
recommended action is to create a formal charter that, at a minimum, conveys a team's responsibilities, defines the team's authority, and identifies core and as-needed members. Charters legitimize teams, particularly when a team must make decisions that affect others external to the team.

Make sure teams understand the change process. Unless a team is responsible for generating ideas, making a recommendation, or solving a problem with a single correct answer, the chances are good that at some point the team must manage the change process, something that will invariably involve others outside the team. This is especially true for teams that structure their work as projects. As highlighted in the third scenario, an inability to manage change can easily undermine success, particularly when performance measurement systems conflict with team goals and objectives.

\subsection{Summary and conclusion}

The results of this research have several overarching policy implications for organizations. First, the formation of organizational work teams should not occur unless careful consideration is given to the kinds of issues and topics presented here (team leadership, size, structure, resources, authority, etc.).Without question effective planning is essential to successful teaming. Second, post-hoc analysis should occur at a team's conclusion or at various intervals for continuously operating teams. Lessons learned and corrective actions identified during these posthoc analyses should be summarized and shared with other teams throughout the organization.

Given a strong reliance on work teams today, organizations must augment what they know about how to design and use teams. Ignoring this increases the risk that organizational leaders will wonder why the reality of using teams does not match the expectations surrounding their use. We should not assume that team members necessarily understand or appreciate how to work as a team. And, even if an organization and its members have a higher intelligence quotient regarding teams, the need to improve is a never ending pursuit. The insights presented here, particularly the findings regarding team size and the team model employed, can further our understanding of how best to benefit from what has become an essential part of most organizations.

\section{References}

Cherry, K., "What is Social Loafing?" http://psychology.about.com/od/sindex/g/socialloafing.htm, retrieved October 2015.

Coutu, D. (2009). Why teams don't work. Harvard Business Review, 87(5): 98-105.

Guzzo, R.A. (1986). Group decision making and group effectiveness, in Designing Effective Work Groups, editor P.S. Goodman. Jossey-Bass Publishers: San Francisco, CA.

Hackman. J.R. (1985). Doing research that makes a difference. Doing Research that is Useful for Theory and Practice, Editor E.E. Lawler. Jossey-Bass Publishers: San Francisco, CA.

Hackman, J.R. (1990). Groups that Work-Creating Conditions for Effective Teamwork, Jossey-Bass Publishers: San Francisco, CA.

Hillman, L.W., Schwandt, D.R., Bartz, D.E. (1990). Enhancing staff members' performance through feedback and coaching. Journal of Management 27.http://dx.doi.org/10.1108/02621719010135110

Hoffman, L.R. (1979). Applying experimental research in group problem solving to organizations. Journal of Applied Behavioral Research, July:375-391.

Kozlowski, S.W.J. and Bell, B.S. (2001). Work Groups and Teams in Organizations, Cornell University ILR School: Cornell, NY, retrieved from http://digitalcommons.ilr.cornell.edu/cgi/viewcontent.cgi?article=1396\&context=articles, 47, 55.

Latane, B., K. Williams, and S. Harkin. (1979). Many hands make light the work. Journal of Personality and Social Psychology, 37: pp. 822-832.http://dx.doi.org/10.1037/0022-3514.37.6.822

Likert, R. (1961). New Patterns of Management. McGraw-Hill, New York, NY, 162.

London, M. (2008).Job Feedback: Giving, Seeking, and Using Feedback for Performance Improvement. Taylor and Francis: Great Britain.

McGrath, J.E. (1984). Groups: Interaction and Performance. Englewood Cliffs, New Jersey: Prentice-Hall.

Peters, L.H. and O'Connors, E.J. (1980). Situational constraints and work outcomes: the influences of a frequently overlooked construct. Academy of Management Review, 5(3):391-397.http://dx.doi.org/10.2307/257114

Stogdill, R.M. (1981). Leaders and their immediate groups. Handbook of Leadership. Free Press, New York, NY, chapter 24.

Takeuchi, H. and Nonaka, I., (1986). The new new product development game. Harvard Business Review, 64(1): 137. 
Trent, R.J., (2004). Team leadership at the 100-foot level. Team Performance Management, 10 (5/6):95100.http://dx.doi.org/10.1108/13527590410556818

Wicker, A.W., Kirmeyer, S.L., Hanson, L., and Alexander, D. (1976). Effects of manning levels on subjective experiences, performance, and verbal interaction in groups. Organizational Behavior and Human Performance, 17(2): 251-274.http://dx.doi.org/10.1016/0030-5073(76)90066-0

Zenger, J., Musselwhite, E., Hurson, K. and Perrin, C. (1994). Leading Teams: Mastering the New Role. Homewood, IL: Irwin: 14-15.

\section{Appendix}

\section{Team Interview Guide}

- Please describe the objectives, goals, and purpose of this team. What was this team assigned to do? How well did team members understand the purpose of the team and their role on it?

- Please describe the process your organization follows when creating teams.

- How experienced or familiar is your organization in using teams?

- Please describe the team model (full time members versus part time; project assignment versus continuous scope of work, cross-functional vs. functional, etc.)

- What was the size of this team? What were the functional backgrounds of the team members? How were the members selected? Do you think team size was too small, just right, or too large?

- Did team members receive any particular training as it relates to working on teams?

- Please see the following topics that may be considered when planning to use teams. Indicate whether or not each item was explicitly considered when forming the team. (Note: Respondents were shown a team planning guide as a reference).

- Did this team have a formal charter? If so, how well was it communicated across your organization?

- Who did this team report to, and how frequently? How did the reporting occur? Did the team receive feedback about its progress and/or performance?

- Did the team have a formally designated team leader? If yes, was this individual effective? Why or why not?

- Given the following 10 items, can you rate the effectiveness of the team leader for each item? (Note: Team members were asked to rate ten responsibilities of an effective team leader).

- On a scale of 1-10 where $10=$ far surpassed expectations, $5=$ met expectations, and $1=$ far below expectations, where would you place this team? If you provided a rating of 8 or higher, what factors do you think were especially important in helping this team be successful? If the team was less successful (a rating of 5 or less), why do you think it was not successful?

- With the benefit of hindsight, what would you do differently the next time as it pertains to using teams at your organization?

- Is there anything that pleasantly surprised you regarding this team or with the process of using teams at your organization?

- Is there anything that occurred that affected team or individual member performance adversely that you did not foresee at the onset?

- Please look at the following listing of items that can affect team performance. Please rate each one in terms of your experience with this team. Are there any items that should be listed that do not appear? (Note: respondents were provided a listing of items that potentially affect team success and asked to rate each item).

- What else can we talk about that we did not cover as it pertains to this team and your experiences with it? 